\title{
Evolution of photography in maxillofacial surgery: from analog to 3D photography - an overview
}

This article was published in the following Dove Press journal:

Clinical, Cosmetic and Investigational Dentistry

30 September 2009

Number of times this article has been viewed

\author{
Heidrun Schaaf \\ Christoph Yves Malik \\ Hans-Peter Howaldt \\ Philipp Streckbein \\ Department of Maxillo-Facial \\ Surgery, University hospital \\ Giessen and Marburg GmbH, \\ Giessen, Germany
}

Correspondence: Heidrun Schaaf University Hospital Giessen and Marburg $\mathrm{GmbH}$, Department of Maxillo-Facial Surgery, Klinikstrasse 29; 35385 Giessen, Germany

$\mathrm{Tel}+4964 \mathrm{I} / 994627 \mathrm{I}$

Fax $+4964 I / 9946279$

Email heidrun.schaaf@uniklinikum-giessen.de; heidrun.schaaf@gmx.net

\begin{abstract}
In maxillofacial surgery, digital photographic documentation plays a crucial role in clinical routine. This paper gives an overview of the evolution from analog to digital in photography and highlights the integration of digital photography into daily medical routine. The digital workflow is described and we show that image quality is improved by systematic use of photographic equipment and post-processing of digital photographs. One of the advantages of digital photography is the possibility of immediate reappraisal of the photographs for alignment, brightness, positioning, and other photographic settings, which aids in avoiding errors and allows the instant repetition of photographs if necessary. Options for avoiding common mistakes in clinical photography are also described and recommendations made for post-processing of pictures, data storage, and data management systems. The new field of 3D digital photography is described in the context of cranial measurements.
\end{abstract}

Keywords: digital, photography, documentation, dental, 3D imaging

\section{Introduction}

As in most technical and medical fields, impressive developments have occurred in recent years in the technological aspects of digital photography and the possibilities of digital documentation. Digital medical photography allows a professional view of novel clinical cases in cranio-maxillofacial surgery. Visualization can be more effective than a verbal description and can aid in making appropriate decisions for treatment.

One of the advantages of digital photography is the possibility of reviewing the picture immediately to judge technical aspects such as sharpness, illumination, color, and patient positioning. The immediate availability of digital images enables the treating physician to monitor a selected aspect in successive or serial shots in the presence of the patient. Fewer appointments with patients may be necessary, as review of the accomplished or planned procedures is possible without waiting for photographs to be processed. Due to the development of powerful data storage tools and software, clinical patient records can be supplemented with informative photographs, and these photographs can be integrated into digital patient files. These improvements along with technical innovations in photography have set the stage for high-quality results in maxillofacial surgery. In the literature, clinical photography is discussed from different viewpoints such as those of plastic and reconstructive surgery, dermatology, dentistry, and orthodontics. ${ }^{1-7}$ Although human life unfolds in a 3-dimensional (3D) setting, most observations and data are captured only in 2 dimensions, and information about the third dimension is left to our judgment. Especially in the medical field, where surgery can change the appearance of a face, 3D assessment is becoming more and 
more essential. This new method will prove its value not only for planning of dental or surgical procedures, but also for predicting the outcome.

Several approaches have been investigated to open the third dimension to the medical world, starting with computerized tomography (CT) ${ }^{8-10}$ ultrasonography, ${ }^{11-13}$ stereolithography, ${ }^{14,15}$ and laser scanners. ${ }^{16,17}$

A detailed review of $3 \mathrm{D}$ craniofacial reconstruction imaging should describe modern imaging techniques most commonly used in medicine and dentistry. Analysis of the whole craniofacial complex, virtual simulation, and real simulation of orthognatic surgery as well as laser scanning with use of stereolithographic biomodeling have been discussed. ${ }^{18}$

The aim of this article is to describe step-by-step the recent developments in medical photography, address solutions for data storage, and highlight the benefits as well as some of the technical and human pitfalls of this technology in the medical profession.

\section{History of digital photography}

In August 1981, the digital camera revolution began when the Sony Corporation released the first commercial electronic handheld camera without film (the Sony Mavica). This was designed as a point-and-shoot camera, which used a charge-coupled device-sensor (CCD-sensor) to record still images to Mavipak diskettes with the equivalent of 0.3 megapixel (MP) resolution. Because the pictures were viewed on a TV screen and could not be processed on a computer, the Mavica was not considered a true digital camera. In 1988, Fuji unveiled the DS-1P as the first true digital camera, which recorded images to a removable static random-access memory (SRAM) card in a computerized file. ${ }^{19}$ The first commercially available digital camera was sold in 1990 as the DYCAM Model 1 or Logitech FotoMan with a resolution of $376 \times 240$ pixels at 256 grayscale levels for a manufacturer's suggested retail price (MSRP) of US $\$ 995 .{ }^{20}$

The next rung on the evolutionary ladder of digital photography was the Kodak DSC-100, shown publicly at the Photokina in 1990 and marketed in 1991 for a MSRP of US\$25,000. It was the first digital single-lens reflex camera (DSLR) consisting of a modified Nikon F3 SLR body and a 1.3 MP digital back. ${ }^{21}$

Although various companies such as Canon, Nikon, Fujifilm, Sigma, Kodak, Pentax, Olympus, Panasonic, Samsung, and Minolta released DSLR cameras intended for professional photographers and early adopters, DSLR cameras could not compete with film-based SLR cameras due to their lack of speed and image resolution. DSLR cameras began to compete with SLR cameras in 1999, when Nikon introduced the Nikon D1, which employed autofocus lenses such as those in current use. In subsequent years, image resolution increased and prices decreased, until the Canon EOS Digital Rebel made DSLR technology available to amateur photographers with a quality comparable to that of film cameras.

\section{Digital workflow in clinical routine}

With further development of CCD resolution, the question was often raised of when or if digital technology would exceed film technology in image quality. This issue has not yet been resolved and depends on numerous parameters. In summary, a resolution of 12 to $16 \mathrm{MP}$ is equivalent to that of ISO 100 color film, but this comparison can only be made when high-quality lenses are used. For image resolution exceeding $10 \mathrm{MP}$, the quality of the lenses and image compression seem to be the limiting factor for image quality. ${ }^{22-24}$ For practical and clinical applications, more detailed image resolution does not yield further advantages, and thus the evolution of the DSLR technique in clinical photography has apparently reached its end.

Considering digital imaging as a tool for routine work in dentistry and oral and maxillofacial surgery, acquired image data must be linked to patient data, maintained, and stored long term. The amount and quality of image data determine the dimensions of the required image storage system.

The best image quality is supplied by unprocessed RAW-image data, which is not recommended in clinical photography due to the degree of post-processing needed and the large file sizes generated. The standardized JPG image format with variable compression, used with a resolution of 6 to $8 \mathrm{MP}$ and low compression, fulfills the requirements of clinical photography and is manageable even for large numbers of images.

In digital workflow, the sharpness, white balance, brightness, and orientation of images should be verified before they are stored in the database. Images should not be post-processed for these parameters, but primarily should be exposed correctly, due to the time-consuming nature of postprocessing and the possibility of falsifying the document. Thus, the ability to immediately control the quality of the picture is a valuable advantage of the digital era.

The requirements for storage of patient images are complex. A patient image database should have a hierarchical structure for user administration, support key-wording, indexing, and savable queries, have a programmable interface for linking image data to a clinical information system 
(CIS), and be fast, scalable, and intuitive to use. Some of the CISs that are currently commercially available support structured data systems with the ability to link an image to a patient file. For more advanced storage and administrative functions, professional digital asset management systems (eg, the Canto ${ }^{\circledR}$ Cumulus) must be integrated into the CIS via a programmable interface. A good compromise for a low-priced image database is to use software such as Adobe Photoshop ${ }^{\circledR}$ Lightroom or ACDSee Pro, which can be used separately from the CIS with few limitations of convenience and function.

As the importance of photography in routine work increases, long-term storage, reliability, and availability become an issue. Although image data can be stored to digital media such as DVDs and Blu-ray ${ }^{\circledR}$ discs, the durability of the image data is threatened by the possibility of hardware failure (due to wear, electrical surge, flood, or fire), accidental deletion, theft, and malicious software. To guarantee permanent availability and safe long-term storage of image data, a multistage strategy must be followed including daily automated backup on a physically separate device, firewalls, a virus scanner, an uninterruptible power source (UPS), surge protection, access control, and a documented emergency and disaster recovery plan.

\section{Standardization of facial medical photography}

A meaningfully defined standard picture set is necessary and can be adapted to the concerns of the respective users. A fullface front view, oblique, submental oblique, and lateral views have been described as a useful basic picture set. Intraoral documentation includes upper and lower occlusal, buccal left and right, and frontal views. ${ }^{2,25}$ Additional picture sets can be obtained for orthognathic surgery, skull deformities, synostotic or positional plagiocephaly, facial palsy, aesthetic surgery, and dental implantology. In dental implantology, the frontal region of the upper jaw is particularly and aesthetically important, and additional close-ups showing neighboring structures are essential. The attention of the surgeon should not focus on the tooth or implant alone, since an implant usually also has effects on the lip and cheek contours of the patient at various ages. A preoperative assessment with the aid of photographs should therefore be included in the planning.

Standardization is indispensable to produce pre- and post-operative photographs that are comparable. One of the fundamental parameters should be the patient's position with the head at the same level as the camera. For each picture, the patient's position and distance from the camera should remain the same, and rotation of the head and tilting must be avoided. The image should be aligned horizontally and vertically to the middle axis of the occlusion plane. For facial pictures, the Frankfort Horizontal Plane should be parallel to the floor and aligned vertical to the occlusion plane. The deformity can be exaggerated or masked if the patient is wrongly position, and this is especially likely to happen with orthognatic patients, as shown in Figure 1. The photograph should be adjusted so that the mid-sagittal plane of the patient is orientated perpendicular to the optical axis. Interfering cosmetics and jewelry should be removed as well as blood or saliva in intraoral views.

\section{D photography}

The brain can achieve 3D perception by interpreting the difference in depth of 2 pictures with the right and left eye.
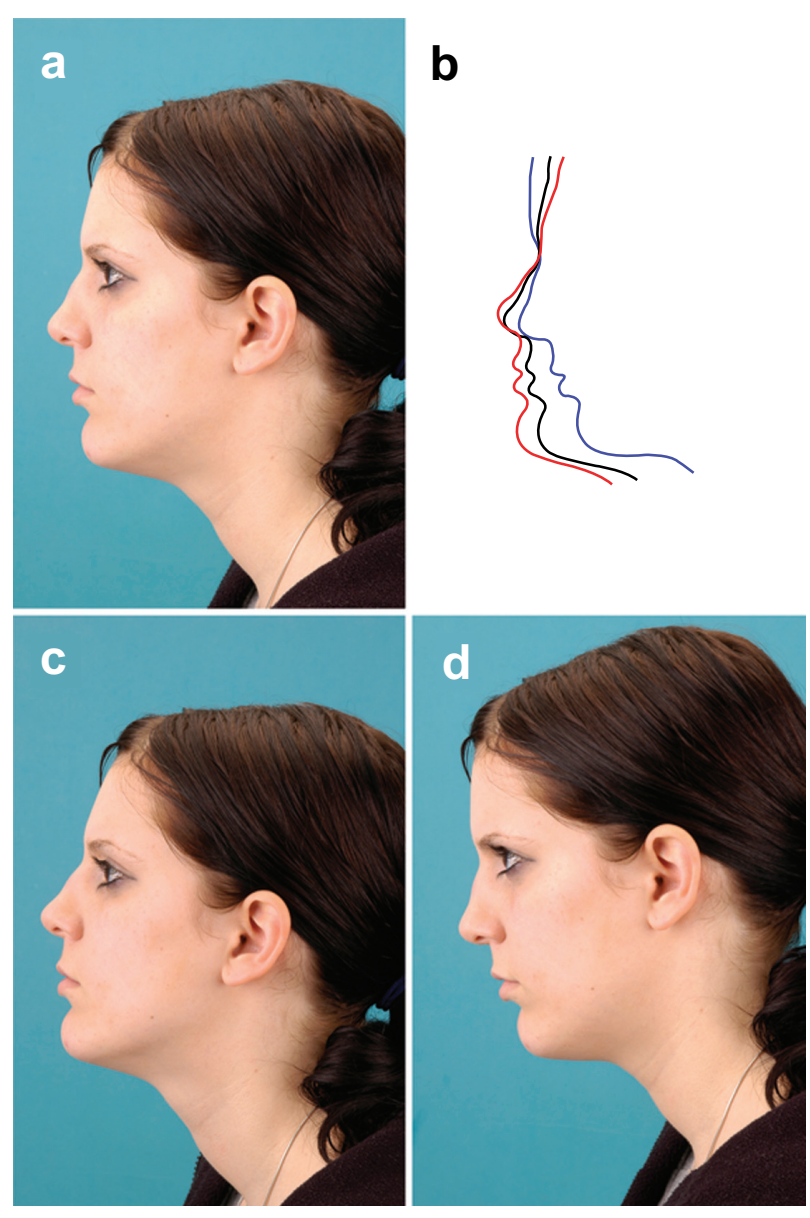

Figure I Lateral view of an orthognatic patient with Angle Class 2. The pictures show markedly different profiles. a) Correct position of the patient; b) tracings of photographs a, c, and d; c) the head is bent backward and the Frankfort Horizontal Plane is not parallel to the ground, and the deformity is therefore underestimated; d) the head is bent forward and the deformity is exaggerated. 
Recently, 3D imaging has been adopted as an innovation in digital photography. The establishment of the next dimension in photography lies in the use of more than one camera at a time. The easiest way to achieve a 3D image is to take 2 pictures of the same object by moving the camera to one side without changing the level. These 2 pictures can now be viewed with 2 eyes using the cross-eye method, looking at the left picture with the left eye and at the right picture with the right eye. The photograph appears $3 \mathrm{D}$ when the images are fused. This method can be learned with patience. More professional ways of producing real $3 \mathrm{D}$ pictures require additional camera viewpoints, and several camera systems have been introduced with this capacity. In 2008, a 3D digital imaging system, the Fuji Finepix Real 3D, was announced, with dual lenses that capture images simultaneously.

\section{Application of 3D digital photography in the medical field}

For medical concerns, other systems with more than two cameras have been investigated, for example the 3D capture systems by Genex ${ }^{\circledR}$ or $3 \mathrm{dMD}^{\circledR}$ (Figure 2 ). The $3 \mathrm{dMD}^{\circledR}$ cranial system, for example, works with five camera viewpoints to obtain a full $360^{\circ}$ picture of the head (Figures 3 and 4). These systems have been analyzed with regard to their anthropometric precision and accuracy of digital 3D photogrammetry of the face, and can be combined or compared with direct anthropometry using statistical methods. ${ }^{26}$ Furthermore, these 3D applications are useful in the description of cranial and facial soft tissues. A meaningful example of their use in medical treatment is the identification of common features in children with craniofacial deformities. The capacity for $3 \mathrm{D}$ visualization supports the ability to

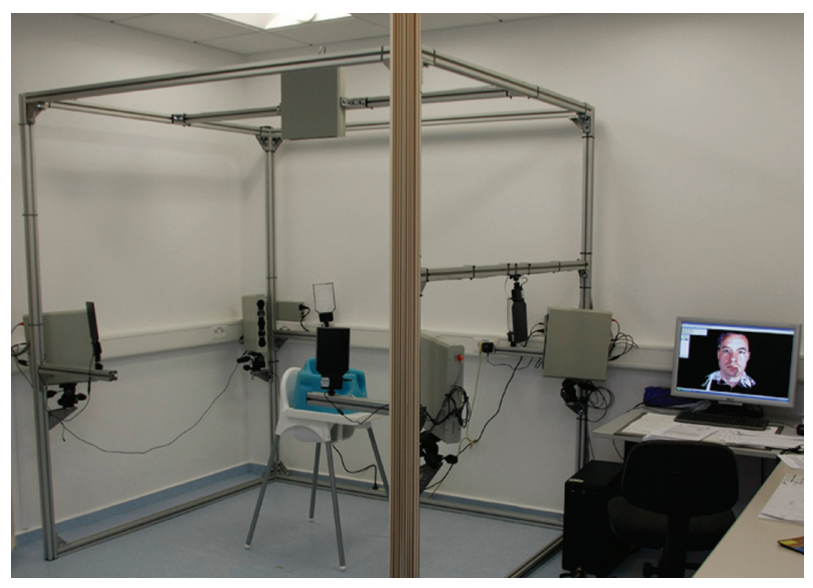

Figure 2 The $3 \mathrm{dMD}^{\circledR}$ cranial system uses 5 camera viewpoints to generate a $360^{\circ}$ image of the head. distinguish synostotic and non-synostotic plagiocephaly. The addition of this feature adds significant information in the diagnosis and treatment of these children.

The use of $3 \mathrm{D}$ photography is of interest in all fields dealing with the treatment of obvious changes in the appearance of facial morphology, both for evaluating changes and predicting surgical results. Applications of 3D imaging for assessment of facial changes have been described in orthodontics as well as in the related discipline of orthognathic surgery. ${ }^{27-31}$ Other authors have described applications in patients with cleft lip and palate ${ }^{32-35}$ or with craniofacial malformations to aid in recognizing the key components of particular syndromes. ${ }^{36}$

New technologies are being implemented in $3 \mathrm{D}$ photogrammetry for collecting phenotypic measurements of the face. ${ }^{37}$ Photogrammetry is more than simply making measurements using stereoscopic photographs, but can capture 3D images with the ability to estimate coordinates of points, linear or surface distances, and volumetric measurements. The more sophisticated computerized stereophotogrammetry, C3D, has been introduced as a useful technique for $3 \mathrm{D}$ recording of monochrome and color stereo images ${ }^{32,38-40}$ in the field of maxillofacial surgical planning.

As previously mentioned, standardization is an essential requirement in clinical and scientific photography, and this has been demonstrated in the field of 3D photography as well. More information is gained with the added dimension, but the number of possible mistakes increases accordingly.

\section{Discussion}

The changeover from analog to digital photography in medicine has occurred gradually and without major difficulties, and the advantages of technologies for digital photography in the dental and maxillofacial field have been clearly outlined; however, the availability of these digital technologies represents both an opportunity and a challenge. The physician is expected to provide sufficient image processing and to ensure the high quality of images. Meaningful archiving and secure storage can be achieved using a professional keyword-indexed asset management system. Such a system provides easy access for presentations and lectures, as well as for forensic purposes. The capability for digital post-processing, however, has the disadvantage of enabling falsification of images.

Many published papers define a basic picture set in 2 dimensions for different uses including dentistry, orthodontics, and maxillofacial and plastic surgery. $2,3,6,25,41$ Furthermore, supplemental picture sets for special 


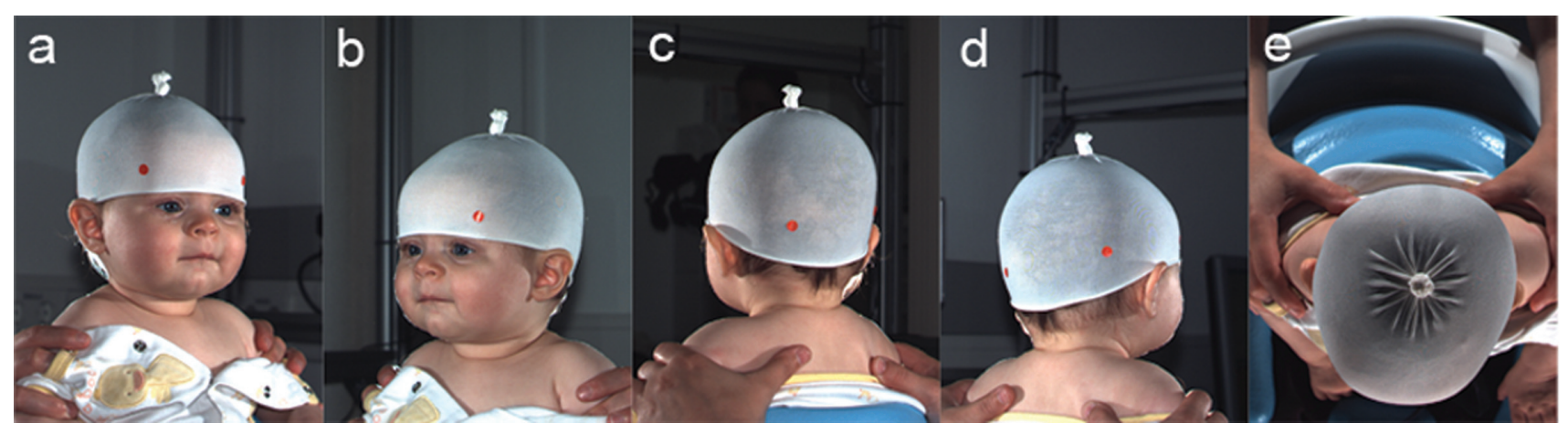

Figure 3 Five camera viewpoints of the head of a patient with deformational plagiocephaly. Camera views: a) half profile front right, b) half profile front left, c) half profile back left, d) half profile back right, e) from above.

circumstances have been described, which are useful in the field of maxillofacial surgery. ${ }^{25}$

Beyond the function of documentation, attempts have been made to use photography as a means of identifying landmarks and measure distances on two-dimensional photographs. Measurements of photographs have been carried out by various specialists, for example, for computerized eyelid measurement analysis in ophthalmology. ${ }^{42}$ Other attempts to characterize facial morphology in orthodontics using standardized photographs have been examined and compared to cephalometric measurements. ${ }^{43,44}$ Photographic methods have also been used to identify landmarks or digitally optimize appliances such as head bands. ${ }^{45-47}$ Nevertheless, reducing the picture set to a minimum will increase acceptance and feasibility. Knowledge of common mistakes can prevent pitfalls and help in achieving professional skills in digital photography. ${ }^{48,49}$ Manipulation of the patient's head position ${ }^{49}$ or changes in illumination ${ }^{50}$ can make a difference in the surgical outcome. The advantages of digital photography such as saving time, lower costs, speed of storage, and reduced storage space with easier access to the photographs, have been described in the literature. ${ }^{2,51}$

The use of 3D photography supports clinical diagnosis and treatment in various fields. In medical genetics, it has demonstrated high levels of sensitivity and specificity in discriminating between controls and individuals diagnosed with Noonan syndrome, and has the potential for use in training physicians. ${ }^{36}$

Precision and error of $3 \mathrm{~d}$ phenotypic measures from $3 \mathrm{dMD}$ photogrammetric images have also been described in the field of clinical dysmorphology in medical genetics. Here the precision is specified as highly repeatable with an error for placement of landmarks in the sub-millimeter range. ${ }^{37}$

The development of CT has revolutionized diagnostic and treatment purposes in medicine. Especially the field of orthognatic surgery has major benefits in the three-dimensional analysis. ${ }^{52}$ The combination of CT-based 3D data sets with 3D photographs could add significant information for tissue landmarks requiring information of hairline or eyelids. It could be shown that the registration of 3D photographs with CT images could provide an accurate match between the 2 surfaces..$^{53}$ Recently this group was able to confirm the accuracy of matching 3D photographs with skin surfaces from cone-beam CTs with an error within $\pm 1.5 \mathrm{~mm} .{ }^{54}$ Using 3D stereophotogrammetry for the soft tissue analysis 2 observers showed a high reliability coefficient with 0.97 for intraobserver and 0.94 for intraobserver reliability in 20 patients. $^{55}$

However, it been reported that the accuracy of 3D facial imaging in orthodontics using the Genex camera system

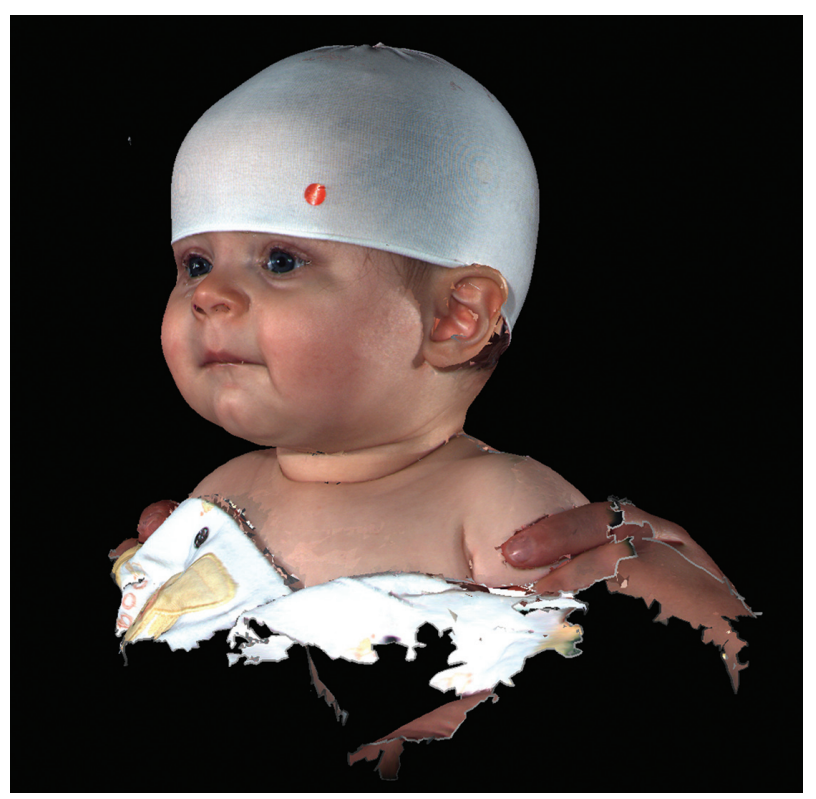

Figure 4 2D illustration of the composed 3D image of the patient's head, which was generated from the 5 views in Figure 3. 
showed substantial image distortion when images of sharp angles $90^{\circ}$ were captured. This system, the Genex Rainbow 3D Camera Model, is a technology with 2 cameras. The accuracy was greater the less that the z-coordinate was incorporated in the image. This limitation was to be expected, given the camera configuration. Because the lenses were located somewhat close to each other, resulting in a limited field of view, it was difficult to get an accurate $\mathrm{z}$-coordinate measurement. ${ }^{31}$

In the medical literature several 3D imaging systems in photography have been introduced. Besides commercially offered systems like 3dMD and Genex, other 3D custom-made systems and software developments have presented. ${ }^{38-40}$ The validation of the systems has been published independently. ${ }^{28,32,37,56}$ The only comparison of measurement data of different 3D photogrammetric systems was performed by Weinberg et $\mathrm{al}^{26}$ and showed that both systems are sufficiently concordant (relative to one another), accurate (relative to direct anthropometry), and precise to meet the needs of most clinical and basic research designs.

\section{Conclusion}

The evolution of photography has resulted in easy-to-use and affordable digital photography for the practitioner. In the specialty of dentistry, medical photography has become a high-quality tool for health care professionals using a defined standard picture set for documentation in a standard reproducible set-up.

The newest innovation in photography, incorporating the third dimension, offers detailed studies of the facial surface and soft tissue morphology. The advantages of digital photography include improved capabilities for diagnostics, planning of surgery and treatment, follow-up, and interdisciplinary communication between physicians and other specialists.

\section{Disclosures}

The authors report no conflicts of interest.

\section{References}

1. Bengel W. Standardization in dental photography. Int Dent J. 1985;35(3):210-217.

2. Ettorre G, Weber M, Schaaf H, Lowry JC, Mommaerts MY, Howaldt HP. Standards for digital photography in cranio-maxillo-facial surgery-Part I: Basic views and guidelines. J Craniomaxillofac Surg. 2006;34(2):65-73.

3. Galdino GM, DaSilva And D, Gunter JP. Digital photography for rhinoplasty. Plast Reconstr Surg. 2002;109(4):1421-1434.

4. Galdino GM, Vogel JE, Vander Kolk CA. Standardizing digital photography: it's not all in the eye of the beholder. Plast Reconstr Surg. 2001;108(5):1334-1344.
5. Jemec BI, Jemec GB. Suggestions for standardized clinical photography in plastic surgery. J Audiov Media Med. 1981;4(3):99-102.

6. Sandler J, Murray A. Digital photography in orthodontics. J Orthod. 2001;28(3):197-201.

7. Sandler J, Murray A. Clinical photographs-the gold standard. J Orthod. 2002;29(2):158-161.

8. Alder ME, Deahl ST, Matteson SR. Clinical usefulness of twodimensional reformatted and three-dimensionally rendered computerized tomographic images: literature review and a survey of surgeons' opinions. J Oral Maxillofac Surg. 1995;53(4):375-386.

9. Guerrero ME, Jacobs R, Loubele M, Schutyser F, Suetens P, van Steenberghe D. State-of-the-art on cone beam CT imaging for preoperative planning of implant placement. Clin Oral Investig. 2006; 10(1):1-7.

10. Xia J, Samman N, Yeung RW, et al. Computer-assisted three-dimensional surgical planing and simulation. 3D soft tissue planning and prediction. Int J Oral Maxillofac Surg. 2000;29(4):250-258.

11. Hell B. 3D sonography. Int J Oral Maxillofac Surg. 1995;24(1 Pt 2): 84-89.

12. Landes CA, Goral WA, Sader R, Mack MG. Three-dimensional versus two-dimensional sonography of the temporomandibular joint in comparison to MRI. Eur J Radiol. 2007;61(2):235-244.

13. Roelfsema NM, Hop WC, Wladimiroff JW. Three-dimensional sonographic determination of normal fetal mandibular and maxillary size during the second half of pregnancy. Ultrasound Obstet Gynecol. 2006;28(7):950-957.

14. Bill JS, Reuther JF, Dittmann W, et al. Stereolithography in oral and maxillofacial operation planning. Int J Oral Maxillofac Surg. 1995; 24(1 Pt 2):98-103.

15. Santler G, Karcher H, Ruda C. Indications and limitations of threedimensional models in cranio-maxillofacial surgery. J Craniomaxillofac Surg. 1998;26(1):11-16.

16. Nakamura N, Suzuki A, Takahashi H, Honda Y, Sasaguri M, Ohishi M. A longitudinal study on influence of primary facial deformities on maxillofacial growth in patients with cleft lip and palate. Cleft Palate Craniofac J. 2005;42(6):633-640.

17. Noguchi N, Tsuji M, Shigematsu M, Goto M. An orthognathic simulation system integrating teeth, jaw and face data using 3D cephalometry. Int $J$ Oral Maxillofac Surg. 2007;36(7):640-645.

18. Papadopoulos MA, Christou PK, Christou PK, et al. Three-dimensional craniofacial reconstruction imaging. Oral Surg Oral Med Oral Pathol Oral Radiol Endod. 2002;93(4):382-393.

19. Larish LL. Understanding Electronic Photography. New York: McGraw-Hill Education; 1990:44.

20. Photography P. Popular Photography. New York: HFM U.S. 1991:111.

21. Photography P. Popular Photography. New York: HFM U.S. 1991:56.

22. Clark RN. Film versus Digital Summary. www.clarkvision.com/ imagedetail/film.vs.digital.summaryl.html 2005. Accessed Nov 23, 2008.

23. Lenhard K. Optik für die Digitale Fotografie. Bad Kreuznach; www.schneiderkreuznach.com/knowhow/digfoto.htm. Accessed Nov 23, 2008.

24. Rockwell K. The Megapixel Myth. La Jolla California. www. kenrockwell.com/tech/mpmyth.htm>. 2006. Accessed Nov 23, 2008.

25. Schaaf H, Streckbein P, Ettorre G, Lowry JC, Mommaerts MY, Howaldt HP. Standards for digital photography in cranio-maxillo-facial surgery - Part II: Additional picture sets and avoiding common mistakes. J Craniomaxillofac Surg. 2006;34(7):444-455.

26. Weinberg SM, Naidoo S, Govier DP, Martin RA, Kane AA, Marazita ML. Anthropometric precision and accuracy of digital three-dimensional photogrammetry: comparing the Genex and 3dMD imaging systems with one another and with direct anthropometry. J Craniofac Surg. 2006;17(3):477-483.

27. Hajeer MY, Ayoub AF, Millett DT. Three-dimensional assessment of facial soft-tissue asymmetry before and after orthognathic surgery. Br J Oral Maxillofac Surg. 2004;42(5):396-404. 
28. Hajeer MY, Mao Z, Millett DT, Ayoub AF, Siebert JP. A new three-dimensional method of assessing facial volumetric changes after orthognathic treatment. Cleft Palate Craniofac J. 2005;42(2): 113-120.

29. Hajeer MY, Millett DT, Ayoub AF, Siebert JP. Applications of 3D imaging in orthodontics: part II. J Orthod. 2004;31(2):154-162.

30. Hajeer MY, Millett DT, Ayoub AF, Siebert JP. Applications of 3D imaging in orthodontics: part I. J Orthod. 2004;31(1):62-70.

31. Lee JY, Han Q, Trotman CA. Three-dimensional facial imaging: accuracy and considerations for clinical applications in orthodontics. Angle Orthod. 2004;74(5):587-593.

32. Ayoub A, Garrahy A, Hood C, et al. Validation of a vision-based, three-dimensional facial imaging system. Cleft Palate Craniofac J. 2003;40(5):523-529.

33. Hood CA, Bock M, Hosey MT, Bowman A, Ayoub AF. Facial asymmetry $-3 \mathrm{D}$ assessment of infants with cleft lip and palate. Int $J$ Paediatr Dent. 2003;13(6):404-410.

34. Hood CA, Hosey MT, Bock M, White J, Ray A, Ayoub AF. Facial characterization of infants with cleft lip and palate using a threedimensional capture technique. Cleft Palate Craniofac J. 2004; 41(1):27-35.

35. Schwenzer-Zimmerer K, Chaitidis D, Berg-Boerner I, et al. Quantitative 3D soft tissue analysis of symmetry prior to and after unilateral cleft lip repair compared with non-cleft persons (performed in Cambodia). J Craniomaxillofac Surg. 2008;36(8):431-438.

36. Hammond P, Hutton TJ, Allanson JE, et al. 3D analysis of facial morphology. Am J Med Genet A. 2004;126(4):339-348.

37. Aldridge K, Boyadjiev SA, Capone GT, DeLeon VB, Richtsmeier JT. Precision and error of three-dimensional phenotypic measures acquired from $3 \mathrm{dMD}$ photogrammetric images. Am J Med Genet A. 2005;138(3):247-253.

38. Ayoub AF, Siebert P, Moos KF, Wray D, Urquhart C, Niblett TB. A vision-based three-dimensional capture system for maxillofacial assessment and surgical planning. Br J Oral Maxillofac Surg. 1998;36(5): 353-357.

39. Ayoub AF, Wray D, Moos KF, et al. Three-dimensional modeling for modern diagnosis and planning in maxillofacial surgery. Int J Adult Orthodon Orthognath Surg. 1996;11(3):225-233.

40. Bourne CO, Kerr WJ, Ayoub AF. Development of a three-dimensional imaging system for analysis of facial change. Clin Orthod Res. 2001;4(2):105-111.

41. Jones M, Cadier M. Implementation of standardized medical photography for cleft lip and palate audit. J Audiov Media Med. 2004;27(4):154-160.

42. Coombes AG, Sethi CS, Kirkpatrick WN, Waterhouse N, Kelly MH, Joshi N. A standardized digital photography system with computerized eyelid measurement analysis. Plast Reconstr Surg. 2007; 120(3):647-656.
43. Ferrario VF, Sforza C, Miani A, Tartaglia G. Craniofacial morphometry by photographic evaluations. Am J Orthod Dentofacial Orthop. 1993;103(4):327-337.

44. Zhang X, Hans MG, Graham G, Kirchner HL, Redline S. Correlations between cephalometric and facial photographic measurements of craniofacial form. Am J Orthod Dentofacial Orthop. 2007; 131(1):67-71

45. Hutchison BL, Hutchison LA, Thompson JM, Mitchell EA. Plagiocephaly and brachycephaly in the first two years of life: a prospective cohort study. Pediatrics. 2004;114(4):970-980.

46. Hutchison BL, Hutchison LA, Thompson JM, Mitchell EA. Quantification of plagiocephaly and brachycephaly in infants using a digital photographic technique. Cleft Palate Craniofac J. 2005;42(5):539-547.

47. Zonenshayn M, Kronberg E, Souweidane MM. Cranial index of symmetry: an objective semiautomated measure of plagiocephaly. Technical note. J Neurosurg. 2004;100(5 Supp1 Pediatrics): 537-540.

48. Nayler J, Geddes N, Gomez-Castro C. Managing digital clinical photographs. J Audiov Media Med. 2001;24(4):166-171.

49. Niamtu J. Image is everything: pearls and pitfalls of digital photography and PowerPoint presentations for the cosmetic surgeon. Dermatol Surg. 2004;30(1):81-91.

50. Ikeda I, Urushihara K, Ono T. A pitfall in clinical photography: the appearance of skin lesions depends upon the illumination device. Arch Dermatol Res. 2003;294(10-11):438-443.

51. Trune DR, Berg DM, DeGagne JM. Computerized digital photography in auditory research: a comparison of publication-quality digital printers with traditional darkroom methods. Hear Res. 1995; 86(1-2):163-170

52. Swennen GR, Schutyser F, Hausamen JE. Three-Dimensional Cephalometry A Color Atlas and Manual. 1st ed. Berlin: Springer; 2005.

53. De Groeve P, Schutyser F, Cleynen-Breugel J, Suetens P. Registration of 3D photographs with spiral CT images for soft tissue simulation in maxillofacial surgery. Med Image Comput Comput Assist Interv. 2001;2208:991-996.

54. Maal TJ, Plooij JM, Rangel FA, Mollemans W, Schutyser FA, Berge SJ. The accuracy of matching three-dimensional photographs with skin surfaces derived from cone-beam computed tomography. Int J Oral Maxillofac Surg. 2008;37(7):641-646.

55. Plooij JM, Swennen GR, Rangel FA, et al. Evaluation of reproducibility and reliability of 3D soft tissue analysis using 3D stereophotogrammetry. Int J Oral Maxillofac Surg. 2009;38(3):267-273.

56. Weinberg SM, Scott NM, Neiswanger K, Brandon CA, Marazita ML. Digital three-dimensional photogrammetry: evaluation of anthropometric precision and accuracy using a Genex 3D camera system. Cleft Palate Craniofac J. 2004;41(5):507-518.
Clinical, Cosmetic and Investigational Dentistry

\section{Publish your work in this journal}

Clinical, Cosmetic and Investigational Dentistry is an international, peer-reviewed, open access, online journal focusing on the latest clinical and experimental research in dentistry with specific emphasis on cosmetic interventions. Innovative developments in dental materials, techniques and devices that improve outcomes

\section{Dovepress}

and patient satisfaction and preference will be highlighted. The manuscript management system is completely online and includes a very quick and fair peer-review system, which is all easy to use. Visit http://www.dovepress.com/testimonials.php to read real quotes from published authors. 